\title{
Prática organizacional de tomada de decisão estratégica: uma contribuição da Teoria da Atividade
}

\section{Organizational Practice of Strategic Decision- Making: a Contribution of Activity Theory}

\author{
DAIANE CORDEIRO DOS SANTOS (D) \\ YARA LÚCIA MAZZIOTTI BULGACOV BD
}

\section{RESUMO}

O processo decisório tem sido um tema central nos estudos organizacionais. Diversas abordagens, teorias e metodologias vêm sendo aplicadas visando compreender a complexidade envolvida nesse processo. A teoria da atividade já foi apontada como promissora nos estudos estratégicos ao evitar o reducionismo. Dentre os teóricos da atividade encontra-se Yves Clot, o qual, ao resgatar Vygotsky, entre outros, dedica-se à análise psicológica do trabalho sob a perspectiva histórico-cultural. Sua teoria, ao considerar o sujeito concreto, possibilita o estudo das interrelações entre cognição e emoção na atividade do trabalho sob uma abordagem prática. Apresenta-se nesse trabalho uma discussão teórica e uma aproximação empírica visando revelar as possibilidades de contribuição da teoria da atividade de Yves Clot para os estudos sobre processo decisório estratégico.

Palavras-Chave: Decisões estratégicas; Emoções; Estudos organizacionais; Teoria da atividade; Psicologia histórico-cultural.

\section{Abstract}

The decision-making process has been a central theme in organizational studies. Several approaches, theories and methodologies have been applied to understand the complexity involved in this process. The activity theory has already been pointed out as promising in strategic studies by avoiding reductionism. Among the 
activity theorists is Yves Clot, who, by rescuing Vygotsky, among others, dedicates himself to the psychological analysis of work from a cultural-historical perspective. His theory, by considering the concrete subject, makes it possible to study the interrelations between cognition and emotion in the activity of work under a practical approach. This paper presents a theoretical discussion and an empirical approach aimed at revealing the possibilities of contribution of Yves Clot's activity theory for studies on the strategic decision-making process.

Keywords: Strategic decision-making; Emotions; Organizational studies; Activity theory; Cultural-historical psychology.

\section{INTRODUÇÃo}

O processo decisório tem sido um tema central nos estudos sobre estratégia organizacional (EISENHARDT; ZBARACKI, 1992; NUTT; WILSON, 2010; STEPTOE-WARREN; HOWAT; HUME, 2011; RAMOS; TAKAHASHI; ROGLIO, 2015; CALABRETTA; GEMSER; WIJNBERG, 2017). Diversas perspectivas foram e/ou são pesquisadas, tais como a racionalidade, a racionalidade limitada, tomadas de decisões não lineares, políticas e relações de poder, intuição, decisões como representações sociais, entre outras, porém, a vertente racionalista ainda é predominante (COHEN; MARCH; OLSEN, 1972; MINTZBERG; RAISINGHANI; THÉORÊT, 1976; CHIA, 1994; LAROCHE, 1995; PAPADAKIS; THANOS; BARWISE, 2010; BULGACOV et al., 2014; RAMOS; TAKAHASHI; ROGLIO, 2015; PATRIA; WAHYUNI; KUSUMASTUTI, 2019).

Visando ir além dessa lógica racional, esse estudo propõe a construção teórica e metodológica do objeto prática de tomada de decisão estratégica. Conforme, Nicolini e Monteiro (2017), dentre os inúmeros conceitos e metodologias desenvolvidos pelos pesquisadores de práticas, alguns pontos comuns demonstram que esta abordagem contribui para se estudar processualmente as organizações, entre eles destaca-se o fato de se considerar que são a partir das e nas atividades realizadas rotineiramente, em determinado tempo e local, que as vidas sociais e organizacionais ocorrem.

Dessa forma, esse estudo fundamenta-se na abordagem prática e nos pressupostos da psicologia histórico-cultural de Yves Clot. $\mathrm{O}$ autor, ao recuperar Vygotsky, entre outros, compõe uma nova 
geração de teóricos da atividade, dedicando-se a análise psicológica do trabalho voltada para a academia e sua aplicação no cotidiano (SANTOS, 2006). Com uma visão complexa do ser humano, Clot $(2006,2010)$ rompe com o cognitivismo ao defender a tese de que não há atividade sem emoção, ao considerar que a emoção potencializa a atividade humana. Para o autor as emoções são socialmente construídas e compartilhadas, são instrumentos psicológicos, os quais estão em constante relação com o pensamento racional e volitivo, conduzindo assim as respostas humanas frente aos conflitos subjetivos decorrentes de sua atividade e organização psíquica (MINICK, 2002; CLOT, 2006, 2010).

A teoria da atividade foi apontada por Jarzabkowski e Wolf (2015) como promissora para os estudos na abordagem da estratégia como prática, pois, centra-se no que as pessoas fazem em um determinado contexto, considera as interações e a dinâmica das atividades, evitando assim o reducionismo.

Fundamentando-se nos pressupostos da psicologia histórico cultural de Yves Clot, sugere-se nessa pesquisa que a prática de tomada de decisão estratégica é um conjunto de atividades humanas interconectadas por uma rede de significados estruturados historicamente e voltadas para um objeto. Pessoal, pois é realizada por sujeitos concretos. Interpessoal ao envolver múltiplos participantes e interesses. Transpessoal ao ser situada histórico-culturalmente, carregar e transmitir memórias e modos de fazer. Sempre mediada por artefatos e instrumentos sócio-culturais, afetivos e históricos. Impessoal, pois é condicionada a estrutura física, legal, tecnológica, administrativa e humana da organização. Mediatizante dos praticantes e gêneros profissionais envolvidos, da própria prática e da organização, resultando em decisões que podem direcionar o futuro organizacional (MINICK, 2002; CLOT, 2006, 2010; BULGACOV; BULGACOV, 2007).

Espera-se que o estudo da prática de tomada de decisão estratégica à luz dos pressupostos da teoria da atividade de Yves Clot, aproxime o pesquisador da complexidade diária vivida pelos tomadores de decisão, contribuindo para o campo teórico e prático dos estudos estratégicos. Desse modo, após a discussão teórica, apresenta-se uma aproximação com o campo empírico, feita pelas pesquisadoras durante uma pesquisa para dissertação de mestrado. 


\section{Práticas Sociais}

Prática Social é um termo explorado por várias áreas da ciência e sob diversas perspectivas - teorias da prática, abordagens práticas, racionalidade prática, ou, simplesmente, práticas - fazem parte de uma família de orientações que visam a compreensão da lógica prática de fenômenos sociais e organizacionais (SANDBERG; TSOUKAS, 2011; NICOLINI; MONTEIRO, 2017).

Sandberg e Tsoukas (2011) argumentam que racionalidade prática considera a totalidade relacional em que os praticantes estão envolvidos, a natureza situacional e o tempo vivenciado, e quando aplicada aos estudos organizacionais, possibilita uma visão clara da realidade organizacional (SANDBERG; TSOUKAS, 2011). Já Reckwitz (2002) defende que a teoria da prática é um tipo de teoria cultural, a qual, por sua vez, é uma maneira de explicar a ação e a ordem social. Além de Jörgen Sandberg, Haridimos Tsoukas e Andreas Reckwitz outros pesquisadores contribuíram com os estudos das práticas, entre eles pode-se citar Pierre Bourdieu, Michel Certeau, Anthony Giddens, Aleksei Leontjev, Theodore Schatzki e Lev Vygotsky, os quais ofereceram ao campo diversas definições (NICOLINI; MONTEIRO, 2017).

Ao analisar múltiplos conceitos, de diversas áreas do conhecimento e de vários autores, Nicolini e Monteiro (2017, p. 3-6) identificaram algumas semelhanças as quais caracterizam uma abordagem prática: as práticas são grandes fenômenos que comportam uma série de subcomponentes que só adquirem sentido quando organizados em torno de um fim ou objeto, que empoderam certos cursos de ação ao desenvolver círculos de poder e com isso influenciam o poder de agência de indivíduos e coletivos sociais; sempre há tensões e inconsistências parciais entre as práticas e seus subcomponentes e entre diferentes práticas, ou seja, desalinhamentos e conflitos são inerentes as práticas; elas são sociais, sancionadas na vida real, materiais, temporal, espacial e historicamente situadas; existem práticas em configurações relacionais, elas nunca são encontradas isoladas; as práticas tem um caráter coletivo e normativo; todas as práticas têm uma história; a indeterminação das práticas permite espaço para iniciativa e criatividade. Os autores argumentam que as "abordagens práticas são 
uma maneira primária de estudar processualmente a organização" (NICOLINI; MONTEIRO, 2017, p. 2, tradução livre).

Dentre os teóricos de práticas encontram-se, na área da psicologia histórico-cultural, os teóricos da atividade, tais como Vygotsky, Leontiev, Engeström e Clot. De modo geral, os teóricos da atividade visam "analisar o desenvolvimento da consciência na atividade social prática." (BULGACOV et al., 2014, p. 651). Sob essa perspectiva, a prática social é tida como objeto de análise a qual deve ser descrita considerando as formas objetivas de atividade, os sujeitos e seus entendimentos - subjetivos e intersubjetivos - em um contexto social (BULGACOV et al., 2014).

Assim, ao considerar a perspectiva de práticas da teoria da atividade nos estudos organizacionais considera-se diversos níveis interligados pelo contexto, rompendo-se com a separação indivíduo-grupo-organização, revela-se conhecimentos implícitos e mediações sociais, apreende-se o fenômeno organizacional no seu momento histórico, como concreto, constituído por sistemas de atividades e causalidades intersubjetivas, evitando-se o reducionismo nos estudos estratégicos (WILSON; JARZABKOWSKI, 2004; BULGACOV et al., 2014; JARZABKOWSKI; WOLF, 2015).

\section{Teoria da ATividade de Yves Clot}

Dentre os teóricos da atividade, Yves Clot compõe uma nova geração de estudiosos, o qual, ao recuperar Vygotsky, entre outros autores, realizou diversos estudos desenvolvendo uma metodologia de pesquisa para o estudo psicológico da atividade do trabalho, denominada por ele de clínica da atividade (CLOT, 2010). Coerente com os pressupostos da abordagem prática e sob a perspectiva psicológico-histórica, Yves Clot (2010) oferece um conceito amplo e complexo de atividade - considerando várias dimensões, entre elas a subjetividade, a coletividade social, a história - e para qual essa seção é dedicada.

Inicialmente cabe esclarecer a distinção que o autor faz entre Atividade Real e Real da Atividade. Para Clot (2010) a Atividade Real é a tarefa realizada, enquanto o Real da Atividade é mais amplo e envolve aspectos subjetivos correlacionado ao poder de ação dos sujeitos. Para compreender o real da atividade é preciso conside- 
rar o sujeito que a realiza como um ser humano concreto, o qual desenvolve-se na interação com os outros, na história transmitida, no seu contexto, em uma relação constante e instável entre emoção e cognição.

Clot (2010) argumenta que a emoção, não é apenas um mediador da atividade humana. As emoções, além de suas dimensões biológicas, são funções mentais com várias atribuições no desempenho da atividade psicológica, inclusive no intelecto. As emoções são instrumentos através dos quais o sujeito responde aos conflitos entre sua atividade e sua organização pessoal, são socialmente construídas e compartilhadas.

O autor assume a visão vygotskyana, na qual a emoção é inicialmente uma função inferior - inconsciente e involuntária - a qual, por meio da linguagem, desenvolve-se nas relações socioculturais, convertendo-se em estruturas interfuncionais complexas, com operações psicológicas novas e elevadas (CLOT, 2010; BRANDÃO, 2012). Mas, as emoções são, ainda, reações aos conflitos entre a experiência já vivida e a realidade viva, ou seja, quando a realidade do presente afeta o equilíbrio interno do sujeito, equilíbrio constituído por suas memórias emotivas e cognitivas, as emoções são respostas a estes desequilíbrios internos. "A emoção é então mais e outra coisa do que uma função psicológica entre outras" (CLOT, 2017, p. 162, tradução livre).

Para Vygotsky a experiência (vivida) emocional juntamente com a experiência (vivida) cognitiva compõem a consciência. A consciência é uma unidade formada por dois processos interconectados, a consciência dos sentimentos ou sensível, e a consciência pensante ou racional. Negando assim, a possiblidade de compreensão do sujeito analisando separadamente seus processos - cognitivo e emocional (CLOT, 2017).

Na teoria vygotskyana, considera-se uma influência mútua entre afeto e pensamento, o sentimento se desenvolve, alterando-se, em um contexto sociocultural, produzindo novos nexos entre sentimento e outras funções psicológicas, assume-se assim o movimento dialético entre sentimento e pensamento (BRANDÃO, 2012). Desse modo, a emoção, ao ser cultivada sobretudo nos sentimentos, envolve o sentido de uma atividade realizada, ou seja, a relação de 
valor entre a ação realizada e as outras possíveis, entre a atividade e o que realmente importa para quem a realiza (CLOT, 2010).

Assumindo que o comportamento do sujeito é a ação vencedora no conflito entre as várias ações possíveis, por meio da emoção, as ações que não foram atendidas permanecem presentes no real da atividade. Desse modo, o Real da Atividade é a atividade realizada mas é, também, a não realizada, a que se tenta realizar mas não consegue, a atividade que o sujeito gostaria ou poderia ter feito no mesmo momento em outro lugar, a atividade procrastinada, o retrabalho e o que foi feito a contragosto. $\mathrm{O}$ real da atividade envolve todas as emoções que os conflitos cognitivos entre estas atividades podem despertar, e é nele que Clot posiciona o conceito de poder de agir. Para o autor, poder de agir refere-se ao poder de ação do indivíduo sobre si mesmo e sobre os outros na situação concreta. O poder de agir depende da saúde física e mental do indivíduo, se desenvolve ou atrofia de maneira alternada entre o sentido e a eficiência no real da atividade (CLOT, 2010).

Após essa explicação inicial de alguns conceitos e pressupostos de Yves Clot, cabe detalhar o que o autor compreende como atividade. Para Clot (2010), a atividade do trabalho é constituída por quatro instâncias: pessoal, interpessoal, transpessoal e impessoal, é mediatizada e mediatizante, conforme será apresentado nos próximos parágrafos.

A atividade é pessoal, do sujeito em seu poder de agir, é formada pela atividade realizada - cognitiva e consciente, mas ela também é constituída pelos dilemas subjetivos onde o sujeito avalia a si - sua experiência - e aos outros, antes de realizar o que deve ser feito (CLOT, 2010). A experiência do sujeito, para Clot (2010, p. 128), é formada pelos "(...) esquemas operatórios, perceptivos, corporais, emocionais ou, ainda, relacionais e subjetivos sedimentados no decorrer da sua vida, que podem ser vistos, também, como um estoque de prontos para agir em função da avaliação da situação (...)". Na auto avaliação, na avaliação em relação ao outro e na avaliação da situação, emoções surgem afetando - nutrindo ou atrofiando - o poder de agir do sujeito. $\mathrm{O}$ autor destaca ainda que por meio da linguagem, na interação social se tem acesso a história e a cultura que situam o sujeito. Os estímulos do contexto, das 
interações e as emoções que estes desencadeiam, em uma relação instável com a cognição, desenvolvem a mente humana. Ou seja, a atividade é pessoal, pois, é realizada pelo sujeito concreto situado histórico-culturalmente (CLOT, 2010).

A história e a cultura carregam as memórias de outras pessoas, assim, estas também se fazem presente na instância interpessoal da atividade, pois, cada sujeito - em sua experiência - carrega em si um pouco dos outros que, mesmo indiretamente e muitas vezes inconscientemente, se fazem presentes. Dessa forma, Clot (2006, 2010), argumenta ainda que a atividade é interpessoal, pois, é dirigida pelo sujeito que a executa, pelo objeto da tarefa e para o outro. Em outras palavras, mesmo quando a atividade parece isolada, ela envolve múltiplos destinatários e seus interesses: o sujeito que a executa e toda a história que este carrega em seu eu, o destinatário da tarefa, o colega de trabalho, e os outros que, mesmo indiretamente e inconscientemente, afetam e são afetados pela atividade realizada.

Ainda considerando a transmissão de memórias, para Clot (2010), a atividade é também transpessoal, mas, para se compreender essa instância é preciso primeiramente entrar eu um outro conceito do autor: de gênero profissional. O gênero profissional refere-se as práticas (nunca definitivas) de um coletivo de trabalhadores, "a memória das emoções de um meio de trabalho" (CLOT, 2006, p. 154), as maneiras de fazer, que conduzem as ações individuais, as quais por sua vez - por meio do estilo profissional de cada sujeito (sua experiência) - mantêm a vitalidade do gênero, ou seja, conservam-no vivo de práticas eficazes, evitando esforços desnecessários, falhas previsíveis e retrabalhos, sendo responsável também pelo desenvolvimento ou não do poder de agir destes (CLOT, 2010).

Logo, é no gênero profissional que se encontra a memória transpessoal da atividade ao conservar e transmitir a sua história social, ao prepará-la, apoiá-la e orientá-la, ao defini-la, organizando atribuições e obrigações. Em outras palavras, pode-se considerar que a atividade é transpessoal, pois, carrega e transmite a história de outras gerações e outros profissionais que já a executaram, servindo de referência para os sujeitos, contribuindo ou dificultando o desenvolvimento do poder de agir destes e, consequentemente, colaborando ou não para a vitalidade do gênero profissional (CLOT, 2010). 
À organização compete, entre outras atribuições, estabelecer as tarefas a serem executadas conferindo impessoalidade a atividade. A prescrição impessoal de tarefas, apesar de sua origem hierárquica, pode ser desenvolvedora de um ofício e estimulante da criatividade profissional, podendo inclusive reconhecer a necessidade de novas atividades. Além disso, ao reconhecer a necessidade de novas atividades ou reorganizar as tarefas existentes, a organização pode ser instituinte de novos objetivos os quais despertam sentimentos de pertencimento ou não nos sujeitos. Desse modo, a impessoalidade da atividade pode ser constituinte, contribuindo para o desenvolvimento do poder de agir - ao sentir-se pertencente do seu meio profissional - ou pode obliterar o poder de agir - quando a solidão se faz presente em meio a várias prescrições impessoais. Assim, a instância impessoal tem um caráter condicionante da atividade e do poder de agir ao possibilitar e, simultaneamente, limitar o desenvolvimento e a criatividade dos sujeitos e, consequentemente, do gênero profissional e da atividade organizacional (CLOT, 2010).

Além das quatro instâncias já citadas, Yves Clot (2010) defende ainda que a atividade é sempre mediatizada por meio de artefatos materiais, da linguagem, dos gestos, do gênero profissional e, inclusive, da atividade dos outros. E mediatizante, operadora de recriação, capaz de produzir novos objetivos, novos destinatários, novas maneiras de executar as tarefas, de construir e reconstruir o mundo do trabalhador, desenvolver novas capacidades, desenvolver o gênero profissional, transformar o próprio sujeito e a organização (CLOT, 2010).

Diante do exposto, ao consolidar todos esses aspectos em uma atividade do trabalho, nota-se que Yves Clot (2010) assume a complexidade do ser humano concreto - emoção e cognição - em sua atividade laborativa, considera as relações sociais sempre existentes, a história e a cultura que permeiam o sujeito e a organização, os artefatos materiais e os instrumentos sociais, a aprendizagem pessoal e organizacional, a relação dialética entre o sujeito e seu contexto, possibilitando uma aproximação real com o dia a dia do trabalho, com o cotidiano organizacional. Demonstrando assim que o desenvolvimento da organização e de seus processos está diretamente relacionado com a ampliação do poder de agir das pessoas que ali 
trabalham. Por sua vez, o desenvolvimento das pessoas, do seu poder de agir, ocorre em uma interrelação contínua entre as funções psicológicas, ou seja, entre a cognição e as diversas emoções que são constantemente despertadas na mente humana.

\section{Processo Decisório Estratégico}

Com potencial para moldar o futuro das organizações, as decisões estratégicas e o processo decisório estratégico têm sido tema central nos estudos organizacionais (EISENHARDT; ZBARACKI, 1992; NUTT; WILSON, 2010; STEPTOE-WARREN; HOWAT; HUME, 2011; RAMOS; TAKAHASHI; ROGLIO, 2015; CALABRETTA; GEMSER; WIJNBERG, 2017). Iniciando com perspectivas mais objetivistas, como a racionalidade e a racionalidade limitada, muitos pesquisadores se dedicaram e ainda se dedicam ao campo, propondo outras visões em busca de uma maior compreensão do fenômeno, entre eles pode-se citar: tomada de decisões não-lineares, política e relações de poder, intuição, decisões como representações sociais, entre outros (LAROCHE, 1995; PAPADAKIS; THANOS; BARWISE, 2010; RAMOS; TAKAHASHI; ROGLIO, 2015; PATRIA; WAHYUNI; KUSUMASTUTI, 2019).

Porém, a vertente racionalista, a qual considera o processo decisório como sistemático e racional, ainda é predominante na literatura. Sob essa perspectiva o processo decisório estratégico tem fases bem definidas, contínuas ou aleatórias, como a identificação de um problema, a definição de prioridades, o levantamento ou desenvolvimento das alternativas possíveis, a avaliação racional - cognitiva - finalizando com a seleção da alternativa (COHEN; MARCH; OLSEN, 1972; MINTZBERG; RAISINGHANI; THÉORÊT, 1976; CHIA, 1994; BULGACOV et al., 2014; RAMOS; TAKAHASHI; ROGLIO, 2015; PATRIA; WAHYUNI; KUSUMASTUTI, 2019).

Laroche (1995) ao questionar a visão racionalista, a exaltação da razão e o cognitivismo predominantes nos estudos do campo, Chia (1994) ao defender a necessidade de uma desconstrução do conceito de decisão visando uma abordagem capaz de compreender a decisão como uma atividade diária, coletiva e contínua, e Hendry (2000) ao argumentar que os conceitos de tomada de decisão estratégicas existentes eram parciais e desconectados dos processos estratégicos reais, considerando que estes podem ser complexos, interativos e multiníveis, são exemplos de um debate 
crescente nas pesquisas no campo das estratégias, inclusive das decisões estratégicas, o qual refere-se à aplicabilidade das teorias de gestão na realidade organizacional.

Visando uma reaproximação entre a academia e as organizações, a utilização da abordagem prática tem sido cada vez mais frequente nos estudos organizacionais, atendendo tanto o público acadêmico - com teorias sobre a prática estratégica, quanto o público profissional - com conhecimentos acadêmicos aplicáveis no desempenhar das atividades (WHITTINGTON, 2003; WILSON; JARZABKOWSKI, 2004; NUTT; WILSON, 2010). Sob a ótica da racionalidade prática, conforme Sandberg e Tsoukas (2011), os conceitos são considerados abertos, ou seja, não são fixos nem totalmente definidos, eles são criações que ajudam na orientação do mundo, porém, suas formas específicas se dão apenas em contextos locais de práticas particulares. Assim, sua utilização nos estudos organizacionais enseja uma aproximação entre a teoria e os gestores, uma vez que permite a compreensão da lógica da prática (SANDBERG; TSOUKAS, 2011).

Entre os estudos organizacionais, a racionalidade prática vem contribuindo para a compreensão das decisões estratégicas ao considerá-las como fenômenos coletivos em que o contexto e as interações sociais podem influenciar a tomada de decisão (CABANTOUS; GOND; JOHNSON-CRAMER, 2010; NUTT; WILSON, 2010; CALABRETTA; GEMSER; WIJNBERG, 2017). Esta, por sua vez, vai além de cálculos - como riscos e custo-benefício - pois, existem escolhas pessoais. Assim, as práticas sociais são enfatizadas, mostrando-se útil para o campo compreender como, nas organizações, os gestores fazem escolhas que envolvem questões estratégicas (NUTT; WILSON, 2010).

A aplicação das teorias das práticas sociais em pesquisas no campo das decisões estratégicas, tem contribuído para uma visão integrada do processo, indo além das perspectivas tradicionais, pois, consideram que as decisões estratégicas são fenômenos histórico e culturalmente situados, sociais e dialéticos (CHIA, 1994; HENDRY, 2000; CABANTOUS; GOND; JOHNSON-CRAMER, 2010; NUTT; WILSON, 2010; CALABRETTA; GEMSER; WIJNBERG, 2017; VILLAR et al., 2018), permitindo a inserção de fatores subjetivos nos estudos do processo de tomada de decisão (VILLAR et al., 2018). 
Aspectos subjetivos do processo de tomada de decisão organizacional foram temas de autores clássicos como Chester I. Barnard e Herbert A. Simon. Barnard (1968) em seu livro The functions of the Executive apresentou reflexões sobre o papel da intuição - aspectos mentais 'não lógicos' - nas decisões. Simon (1987), resgatando Barnard, abordou a intuição e a influência das emoções estressantes nas tomadas de decisão. Nesse estudo, o autor distingue decisões "não racionais" das "irracionais", explicando as "não racionais" como derivadas da intuição e do julgamento, baseadas na experiência e no treinamento do tomador de decisão, e as "irracionais" como aquelas que podem ser produzidas pelas emoções estressantes (SIMON, 1987, p. 62, tradução livre).

Maitlis e Ozcelik (2004, p. 375, tradução livre), após um estudo etnográfico de dois anos, propuseram o conceito de processos de decisão tóxicos: "processos de decisão organizacional que geram emoções negativas generalizadas em uma organização através da interação recursiva das ações e emoções negativas dos membros." Os autores argumentaram que as emoções interagem mesmo com modelos de decisões como escolhas racionais, baseadas em regras e políticos, defendendo que a inclusão das emoções pode contribuir para o desenvolvimento das pesquisas sobre tomada de decisão.

Nos últimos 10 (dez) anos diversos pesquisadores vêm se dedicando a pesquisar a subjetividade nas decisões estratégicas, como pode ser visto por exemplo, nos estudos de Steptoe-Warren, Howat e Hume (2011), Cabantous, Gond e Johnson-Cramer (2010), Elbanna (2018) e Nolsen (2018). Entre os estudos dedicados à fatores subjetivos das decisões estratégicas, as emoções vêm sendo pesquisadas sob diferentes aspectos e abordagens metodológicas. Por exemplo, utilizando abordagens qualitativas foram publicados os estudos de Ericson (2010), Hodgkinson e Healey (2011), Bodolica e Spraggon (2011), Harbour e Kisfalvi (2014), Neumann (2017) e Gear et al. (2017). Utilizando abordagens quantitativas apresentam-se as pesquisas de Parayitam, Olson e Bao (2010), Fodor, Curşeu e Fleştea (2016) e Treffers, Klarner e Huy (2020).

Diversas perspectivas teóricas também são encontradas, tais como, neurociência cognitiva social (HODGKINSON; HEALEY, 2011), sensemaking (ERICSON, 2010), teoria da avaliação (GEAR 
et al., 2017; NEUMANN, 2017), teoria dos eventos afetivos (NEUMANN, 2017), teoria do processo de grupo (PARAYITAM; OLSON; BAO, 2010), visões cognitivistas (HODGKINSON; HEALEY, 2011; HARBOUR; KISFALVI, 2014; GEAR et al., 2017; NEUMANN, 2017) e behavioristas (PARAYITAM; OLSON; BAO, 2010; BODOLICA; SPRAGGON, 2011; TREFFERS; KLARNER; HUY, 2020).

Porém, apesar dessa diversidade nas pesquisas e do reconhecimento da importância de se estudar o papel das emoções nas decisões estratégicas o campo ainda está começando a se desenvolver (NEUMANN, 2017). Entre as necessidades de pesquisas futuras encontra-se, por exemplo, analisar a natureza das emoções na tomada de decisão estratégica e do contexto emocional na coragem dos gestores (HODGKINSON; HEALEY, 2011; HARBOUR; KISFALVI, 2014); necessidade de analisar os efeitos das emoções e da regulação destas na tomada de decisão estratégica (HODGKINSON; HEALEY, 2011; FODOR; CURŞEU; FLEŞTEA, 2016); abordar o sentido, reconhecer as crenças e emoções como guias, e a complementariedade entre a racionalidade e a emoção nas decisões estratégicas (ERICSON, 2010); identificar a existência e o poder de influência das emoções sobre o processo decisório (NEUMANN, 2017); analisar a relação entre cognição, emoção e processos decisórios estratégicos (GEAR et al., 2017); investigar o papel do tempo e das emoções dos tomadores de decisão; analisar aspectos psicológicos de grupos de atores que influenciam as decisões estratégicas, bem como, de emoções coletivas (TREFFERS; KLARNER; HUY, 2020).

Diante do exposto, nota-se a evolução do campo de pesquisas sobre decisões estratégicas, com teorias descritivas e prescritivas que abrangem uma amplitude de fatores envolvidos, pesquisadores aproximam-se da realidade contribuindo para a teoria e o dia a dia organizacional. Porém, a predominância do racionalismo científico, do objetivismo e do cognitivismo nos estudos, oferece a perspectiva de decisores frios, ou, nas palavras de Nutt e Wilson (2010), uma perspectiva desumanizada, com maiores contribuições para a caracterização do processo decisório estratégico do que para a compreensão de como os indivíduos realizam este processo (CHIA, 1994; LAROCHE, 1995; BULGACOV et al., 2014; RAMOS; TAKAHASHI; ROGLIO, 2015; PATRIA; WAHYUNI; KUSUMASTUTI, 2019). 
Ao se adotar a teoria da atividade de uma perspectiva psicológica-histórica nas pesquisas sobre decisões estratégicas, afasta-se da cognição fria, considera-se o sujeito complexo, a importância do contexto e da história (CLOT, 2006, 2010; HODGKINSON; HEALEY, 2011). Os processos decisórios estratégicos são realizados por pessoas, sujeitos singulares, logo, assumir estes em sua completude, considerando sua racionalidade e subjetividade contribui para a compreensão aprofundada desses processos.

Assim, ao se basear nos pressupostos teóricos-metodológicos de Yves Clot (2006, 2010), enfatiza-se a associação entre emoção (subjetividade) e cognição no processo decisório estratégico, indo ao encontro de uma necessidade do campo, conforme indicado por Ericson (2010), Hodgkinson e Healey (2011), Gear et al. (2017), Neumann (2017), Treffers, Klarner e Huy (2020). Permite complementar a compreensão do pensamento racional, ao revelar que a consciência e a experiência dos praticantes são compostas também pelas emoções.

\section{Prática de Tomada de Decisão Estratégica À LuZ doS Pressupostos da Teoria da Atividade de Yves Clot}

Sugere-se nessa pesquisa os pressupostos teóricos de Yves Clot como uma alternativa para a análise da prática de tomada de decisão estratégica, contribuindo para os estudos organizacionais, ao possibilitar uma abordagem complexa do processo decisório estratégico. A perspectiva teórica de Clot (2010) converge com a abordagem relacional proposta por Wilson e Jarzabkowski (2004), considerando diversos níveis interligados pelo contexto, as interações e o resultado - nesse estudo, a decisão estratégica - visando evitar o reducionismo extremo dos estudos sobre estratégia organizacional (JARZABKOWSKI; WOLF, 2015).

Inicialmente cabe destacar dois conceitos básicos para este desenvolvimento teórico, os conceitos de ação e atividade. Ação é um ato derivado do poder de agir do sujeito concreto, direcionado a um objeto, envolve o pressuposto operacional - conhecimentos técnicos e instrumentos materiais necessários - e o pressuposto subjetivo construído socialmente e intrasubjetivamente - a motivação, o sentido para agir, as emoções. Já a atividade é um conjunto de ações interconectadas, voltadas para um objeto, situada histórico-cul- 
turalmente, pessoal, interpessoal, transpessoal, impessoal, sempre mediatizada e mediatizante, conforme apresentado anteriormente (CLOT, 2006, 2010).

Baseando-se nos pressupostos teóricos do real da atividade de Yves Clot (2010), sugere-se nessa pesquisa que a prática de tomada de decisão estratégica é, primeiramente, um conjunto de atividades humanas interconectadas por uma rede de significados estruturados historicamente, voltadas para um objeto, um fim, o que precisa ser decidido. Ela também é situada histórica e culturalmente, ou seja, para compreendê-la em todas as suas especificidades necessita-se compreender o sentido e o significado que a permeiam, e para isso é preciso considerar o contexto histórico-cultural em que está sendo realizada: o gênero ou gêneros profissionais presentes, o momento histórico, a história da organização e, quando for o caso, da unidade organizacional em análise.

As práticas são coletivas e mutáveis, já existem antes mesmo dos praticantes entrarem na organização, estabelecem um senso normativo, organizando, controlando e dirigindo a atividade humana, constituindo um meio de socialização e transferência de competências aos novos ingressos, sendo que qualquer realização futura das práticas tanto corrobora quanto renova o contexto existente (NICOLINI; MONTEIRO, 2017; VILLAR et al., 2018). Ao assumir a transpessoalidade das atividades constituintes da prática, amplia-se esse entendimento, ao argumentar que a prática conserva e transmite também, por meio do gênero profissional, uma memória emocional, ou seja, o meio de socialização e transferência de competências é composto também pela memória das emoções e como estas afetam os comportamentos dos praticantes (CLOT, 2006, 2010).

Não há como se falar em prática sem praticante, assim, a prática de tomada de decisão estratégica é pessoal, realizada pelo sujeito concreto, um ser racional e emotivo, com poder de agir, com experiência - esquemas relacionais e subjetivos consolidados, mentalmente constituído em suas interações sociais e portador de uma história de vida (CLOT, 2010). Essa instância tem um papel de relevância para a prática de tomada de decisão estratégica, pois, utilizando as palavras de Clot (2010, p. 128), a experiência do sujeito refere-se ao "estoque de prontos para agir" na avaliação da situação. Portanto, 
o 'tamanho' desse estoque pode ser fundamental para se agir com eficiência e eficácia, principalmente, quando o tempo é escasso.

A prática de tomada de decisão estratégica é, também, interpessoal, envolve múltiplos interesses, do praticante e do gênero profissional que este representa, do destinatário direto e dos outros. Esses múltiplos interesses, por meio das emoções que podem ser, por exemplo, a preocupação e/ou o afeto com o outro e a submissão e/ou confiança em um gênero, afetam o poder de agir e, consequentemente, a prática de tomada de decisão estratégica (CLOT, 2010).

A mediação entre o praticante e o objeto e entre diversos praticantes se dá, por exemplo, por meio de artefatos materiais - tais como: atas, pautas, documentos e equipamentos - da linguagem, dos gestos, do gênero ou gêneros profissionais presentes (maneiras de fazer e memórias emocionais), os quais compartilham sentido entre os diversos participantes, e pela emoção (CLOT, 2010). Isto posto, a prática de tomada de decisão estratégica é sempre mediatizada.

A prática de tomada de decisão estratégica é, ainda, impessoal, condicionada pela organização, a qual prescreve a tarefa - nesse caso o objeto. Ao ser considerada situada, a prática nunca será a mesma - ainda que o objeto venha a se repetir, serão diferentes momentos (tempo e contexto) e, frequentemente, diferentes participantes - de tal forma que sempre será necessário algum nível de adaptação, de iniciativa, de criatividade por parte dos envolvidos. Porém, os envolvidos estão condicionados aos limites organizacionais, ou seja, as possibilidades e limitações impessoais para a criatividade e o desenvolvimento do poder de agir dos praticantes (CLOT, 2010; NICOLINI; MONTEIRO, 2017).

Ao se referir em desenvolvimento do poder agir revela-se o caráter mediatizante da prática de tomada de decisão estratégica, ou seja, a capacidade de alterar positiva ou negativamente os participantes, o gênero profissional, a própria prática e a organização, por meio de uma constante interação dialética (CLOT, 2010). Abaixo, a figura 1, visa ilustrar o modelo teórico da prática de tomada de decisão estratégica à luz dos pressupostos da teoria da atividade de Yves Clot. 


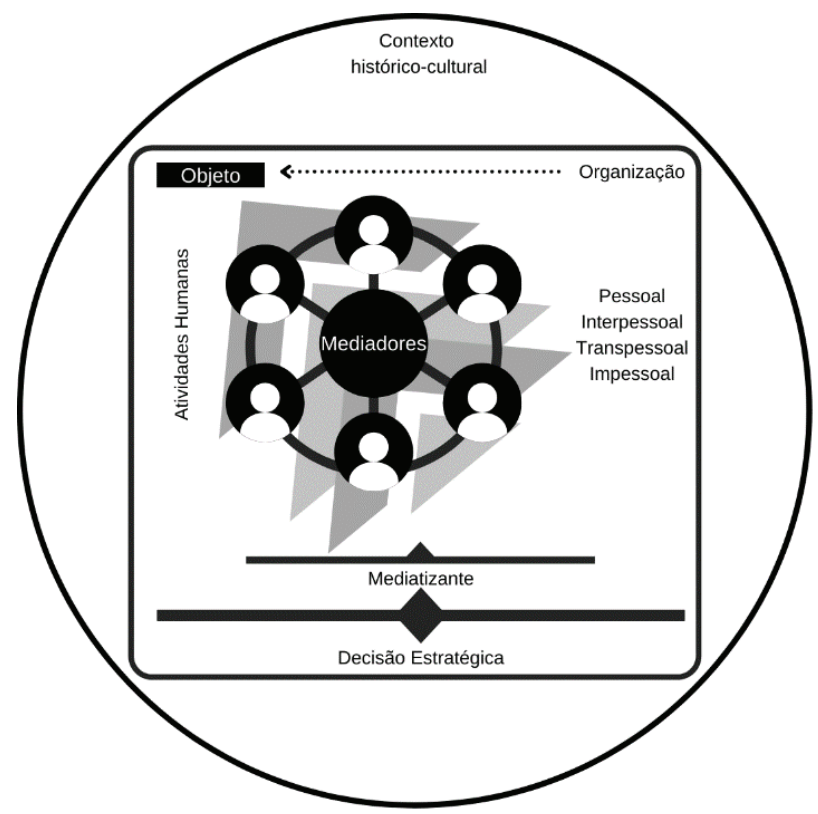

Figura 1: Modelo teórico de Prática de tomada de decisão estratégica Fonte: As autoras (2021)

Resumidamente, baseando-se na teoria da atividade de Yves Clot (2010), sugere-se nessa pesquisa que a prática de tomada de decisão estratégica é um conjunto de atividades humanas interconectadas por uma rede de significados estruturados historicamente e voltadas para um objeto. Pessoal, pois é realizada por sujeitos concretos. Interpessoal ao envolver múltiplos participantes e interesses. Transpessoal ao ser situada histórico-culturalmente, carregar e transmitir memórias e modos de fazer. Sempre mediada por artefatos, instrumentos sócio-culturais, afetivos e históricos. Impessoal, pois é condicionada a estrutura física, legal, tecnológica, administrativa e humana da organização. Mediatizante dos praticantes e gêneros profissionais envolvidos, da própria prática e da organização, resultando em decisões que podem direcionar o futuro organizacional (MINICK, 2002; BULGACOV; BULGACOV, 2007).

Na próxima seção apresenta-se, como exemplo de aplicação empírica do objeto aqui proposto, dados iniciais de uma pesquisa realizada pelas autoras visando a apreensão da dimensão afetiva- 
-cognitiva na prática de tomada de decisão estratégica no contexto da pandemia do coronavírus.

\section{APROXIMAÇÃo EMpírica}

Visando compreender a dimensão afetiva-cognitiva na prática de tomada de decisão estratégica no contexto da pandemia do coronavírus, desenvolveu-se uma pesquisa qualitativa baseada na ontologia e no fenômeno da prática (ORLIKOWSKI, 2015). Clot (2006, 2010, p. 11) argumenta que a atividade é "a menor unidade de intercâmbio social", possibilitando a compreensão e a explicação das situações de trabalho. Diante disso e coerente com as abordagens práticas, a pesquisa assumiu a própria prática como unidade de análise (NICOLINI; MONTEIRO, 2017). Voltada para as especificidades, o caso foi uma instituição pública de ensino superior do Paraná, e a prática pesquisada foi a gestão das atividades acadêmicas durante a pandemia do coronavírus.

A pesquisa utilizou dados secundários como documentos, vídeos e notícias, coletados em diferentes fontes virtuais, website oficial, perfil oficial na rede social Facebook, e contas oficiais no Youtube, além de outros meios confiáveis de comunicação, tais como websites da administração pública. A observação não participante e as entrevistas foram utilizadas para coletas de dados primários (ORLIKOWSKI, 2015).

Todos os vídeos coletados foram observados visando a apreensão dos sentidos e significados compartilhados, dos gestos, das vozes, de expressões faciais, de emoções, bem como, a compreensão da dinâmica relacional existente, resultando em notas da própria pesquisadora.

A técnica para análise dos dados foi a abordagem configuracional proposta por Nicolini e Monteiro (2017) a qual visou compreender as práticas a partir da análise de como realizações e ações estão conectadas espaço-temporalmente. Após a análise das notas e dos dados secundários, a prática decisória estratégica foi descrita com todos os detalhes apreendidos. Essa descrição foi utilizada posteriormente nas entrevistas.

Participantes da prática pesquisada foram convidados a conceder entrevistas baseadas nos pressupostos metodológicos da au- 
toconfrontação simples de Yves Clot. Na autoconfrontação simples o pesquisador, por meio de registros feitos previamente, promove um encontro do sujeito (trabalhador) com sua própria atividade de trabalho, possibilitando a reflexão e ressignificação do trabalhador em relação a sua própria atividade, e uma investigação aprofundada para o pesquisador $(2006,2010)$.

Assim sendo, primeiramente foi enviado um arquivo de texto aos entrevistados, no qual era apresentada brevemente a prática de tomada de decisão estratégica pesquisa: o contexto histórico-cultural, as atividades constituintes e suas interrelações organizadas em ordem cronológica, as ações identificadas, os gêneros profissionais envolvidos, os mediadores, as emoções identificadas, os sentidos e significados compartilhados e apreendidos. Essa descrição contextualizava e situava o entrevistado, permitia, por meio de um reencontro com a prática, sua reflexão sobre as especificidades daquela prática em relação a outras que já havia participado (CLOT, 2006, 2010; CARVALHO; AGUIAR; ALFREDO, 2020).

As entrevistas foram realizadas de modo remoto, por meio da plataforma Microsoft Teams, todas foram gravadas e literalmente transcritas para posterior análise das expressões faciais, das vozes e das narrativas. Narrativas, nessa pesquisa, foram consideradas construções discursivas, temporais e que fornecem um meio para criação de sentido, as quais foram utilizadas como fonte de dados para apreensão das categorias analíticas (VAARA; SONENSHEIN; BOJE, 2016). Todos os dados foram analisados e triangulados visando apreender as relações entre dizeres e fazeres, entre emoção e cognição, a dimensão afetiva-cognitiva (CLOT, 2006, 2010; ROULEAU, 2015; NICOLINI; MONTEIRO, 2017). Nessa publicação são apresentadas as análises apenas dos dados secundários e de uma entrevista piloto.

Isso posto, a partir dos dados analisados, a prática de tomada de decisão estratégica pesquisada teve por objeto a gestão das atividades acadêmicas de uma instituição pública de ensino superior paranaense diante da pandemia do coronavírus e foi caracterizada como um conjunto de atividades interconectadas - cotidianas (identificação e caracterização de problemas, definição de prioridades, levantamento e análise de alternativas) e decisórias (escolha e im- 
plementação das melhores alternativas), que em alguns momentos ocorreram simultaneamente.

Essas atividades foram constituídas por um conjunto de ações, tais como pesquisas aplicadas a comunidade acadêmica, levantamentos de dados e mapeamentos contextuais. Ações realizadas por pessoas, sujeitos complexos - que pensam, sentem e agem - e experientes. Pessoas que são afetadas pelo contexto, que se preocupam com outras pessoas e outros interesses, que se emocionam com vidas perdidas, pessoas que carregam memórias, pessoas com poder de agir, com capacidade de reflexão e criação:

"A gente sempre brinca né, você toma decisão com base em experiências passadas, e essa era infelizmente uma experiência inusitada, nova, que realmente foi muito complicada para a gente. Então, o que que nós tentamos ao longo desse processo: compartilhar o máximo de informações internas e externas; tentar um 'benchmarking', mas o que as irmãs estão fazendo? (...) o que as universidades de fora estão fazendo? para que a gente pudesse criar uma inteligência básica para saber que caminho a gente deveria tomar." (Entrevistado A)

Os dados evidenciam a presença da afetividade, das emoções na prática de tomada de decisão estratégica. Observa-se que, mesmo quando os praticantes ressaltam a lógica racional, a dimensão afetiva se faz presente, demonstrando a relação dialética entre cognição e emoção no poder de agir dos praticantes. Apresenta-se dados técnicos, mas também se fala sobre apreensão, ansiedade, empatia. Em entrevista observa-se a presença da dimensão afetiva-cognitiva, e sua relação com o contexto que estava sendo vivenciado, e a mediação da emoção na prática de tomada de decisão estratégica:

“(...) naquele momento o que a gente estava querendo, reduzir o prejuízo humano né, o prejuízo de perda de vidas, infecção, (...). Se fosse em outro momento, que não fosse mexer com vidas humanas, (...), aí o racional toca a frente. Mas diante desta situação em específico, o lado afetivo, as emoções, bom cada um quando ia nas reuniões, quando a gente estava preparando o que fazer, como retomar, vinha muito esse lado afetivo, esse lado da emoção, olha morreu fulano, 
a cuidado, lá na Itália, era muito, lá na Itália, porque lá na Itália, lá na Espanha, não era no Brasil, era lá. Mas mesmo assim, vinha uma carga emocional muito forte no debate das decisões." (Entrevistado A).

A interpessoalidade da prática de tomada de decisão estratégica pesquisada é revelada pela participação de diversos praticantes, internos e externos à universidade, representantes de gêneros profissionais como: administração central da universidade, docentes, discentes, servidores técnicos, especialistas em saúde, administrações públicas municipal e estadual de saúde, gestores universitários de outras instituições e comunidade externa, condicionados à organização pesquisada, a qual estava situada em um contexto incerto de pandemia.

Esses dados demonstram os múltiplos interesses envolvidos - dos praticantes, dos destinatários (nesse caso, especificamente, os discentes) e dos gêneros profissionais representados - os quais podem ser revelados também por meio de entrevistas, como exemplifica os trechos de fala do entrevistado A:

"A primeira coisa que nos pegou de surpresa era que a gente estava decidindo sobre uma coisa nova, sem previsão e sem muita informação. (...) estava todo mundo assim, cada um tem suas pressões institucionais, (...) enquanto gestão nós trocávamos as nossas informações para ver o que poderia ser menos danoso, menos complicado."

A transpessoalidade na prática de tomada de decisão estratégica pesquisada se revelou nos dados secundários, quando a história da universidade é citada como um ponto positivo que contribuiria para a construção de uma alternativa que atendesse a grande diversidade universitária e as demandas que o contexto do coronavírus impunha, como o distanciamento social, por exemplo. Sua relevância foi identificada também por meio da entrevista: "A universidade, pelo tempo de ação dela, de existência, pela história que ela construiu, ela não sofreu tanto." (Entrevistado A).

Diante do contexto da pandemia do coronavírus, observou-se uma alteração significativa nos artefatos mediadores da prática de tomada de decisão estratégica pesquisada. Inicialmente com reuni- 
ões realizadas de modo presencial e, com o passar do tempo sendo realizadas de modo remoto, para atender os protocolos de saúde, os principais artefatos mediadores foram os documentos (leis, resoluções, despachos, portarias, medidas provisórias, pareceres da comissão de especialistas, notícias de diferentes mídias, posicionamentos formais de representantes da comunidade e resultados de pesquisas internas) e as ferramentas tecnológicas (computadores, smartphones, internet, softwares e plataformas de comunicação remota).

Além dos artefatos houve mediação das emoções (apreensão, ansiedade, empatia, apatia, vigilância, segurança e alegria, por exemplo), da linguagem (fala, gestos, textos e língua brasileira de sinais) e dos gêneros profissionais (administração central da universidade, docentes, discentes, servidores técnicos, especialistas em saúde, administrações públicas municipal e estadual de saúde, gestores universitários de outras instituições e comunidade externa).

A prática de tomada de decisão estratégica pesquisada foi uma demanda da administração central da universidade diante do contexto do coronavírus, das recomendações científicas, do plano de desenvolvimento institucional e das necessidades da comunidade, ou seja, foi prescrita impessoalmente pela instituição. Além de prescrita ela também foi viabilizada, por meio, por exemplo, da estrutura física e tecnológica disponibilizada e de pessoas qualificadas. Conforme ilustra o relato feito pelo entrevistado A:

“(...) eu acho que a estrutura da universidade ela forneceu subsidio suficiente para que isso não fosse tão traumático. "Você tem uma resistência muito grande, só que essa estrutura, tecnológica, de capacitação de professores, servidores, até essa dispersão geográfica isso 'ajudou' a ganhar, acumular experiência para que pudesse ser aplicado nesse período novo que a gente está vivendo (...)".

Porém, a prática decisória estratégica foi ainda limitada impessoalmente pela instituição. Limites estes estabelecidos por diversos fatores, tais como a legislação vigente, a estrutura física e tecnológica disponível, a capacidade e possibilidade de investimentos, a inclusão digital de alunos, docentes e servidores, o tempo e as premissas universitárias. 
Ademais, a prática de tomada de decisão estratégica pesquisada revela seu caráter mediatizante sobre o praticante em seu poder de agir como consequência da alteração na dinâmica da prática, exigindo de alguns praticantes a inclusão e o letramento digital, ou seja, o desenvolvimento de novos conhecimentos em relação a ferramentas tecnológicas de acesso remoto, vídeo conferência, softwares e plataformas de comunicação remota, sistemas digitais, entre outros.

Porém, é preciso considerar que essa exigência de adaptação as ferramentas tecnológicas podem afetar o poder de agir dos praticantes, positiva ou negativamente. Positivamente se houver o desenvolvimento de novos conhecimentos e habilidades por parte de praticante e esse sentir-se seguro, capaz para sua utilização. Mas, se o praticante tiver muitas dificuldades, sentindo-se incapaz ou inseguro, por exemplo, seu poder de agir pode ser reduzido.

A alteração na dinâmica da prática, ressalta ainda a necessidade de desenvolver formas de deliberação em situações de dificuldades de comunicação, de diálogo, como é o caso do contexto da pandemia do coronavírus, e de inovação nos métodos e metodologias de ensino até então utilizadas, exigindo reflexão e criatividade dos praticantes.

Por fim, as decisões tomadas nessa prática, impactaram diretamente em questões estratégicas da universidade pesquisada, uma vez que foram assuntos relacionados ao ensino, que é o principal pilar estruturante do seu planejamento estratégico. Decisões relacionadas aos calendários acadêmicos, por exemplo, os quais refletem em consequências importantes para a gestão universitária. Além disso constatou-se ainda que a prática de tomada de decisão estratégica pesquisada não se encerrou na última decisão analisada. Para pesquisa foi necessário um recorte temporal, porém, a última decisão estratégica desencadeou um novo objeto que dará início a uma nova atividade constituinte dessa prática, não sendo possível afirmar quando o processo foi ou será encerrado.

\section{CONSIDERAÇões FinAIS}

A pesquisa baseada nos pressupostos teóricos-metodológicos de Yves Clot (2006, 2010), permite uma análise multinível, ao considerar o sujeito (praticante) na prática situada em um contexto histórico-cultural. Tal análise, revelou, por exemplo, a participação de praticantes externos 
à organização. Revelou ainda, no caso pesquisado, decisões estratégicas como fenômenos sociais, coletivos e interativos, construídos pela participação de praticantes de diversos gêneros profissionais, que voltados para um objetivo defendem diversos interesses.

A partir do conceito de real da atividade de Yves Clot $(2006,2010)$ também é possível se aproximar do dia a dia dos gestores e tomadores de decisão, pois, rompe-se com a racionalidade lógica, considerando a dimensão afetiva, revelando, por exemplo a mediação das emoções na prática de tomada de decisão estratégica. Evidenciando que as emoções, juntamente com a cognição e a volição, estão presentes nos processos decisórios estratégicos. Destacando a complexidade envolvida na prática de tomada de decisão estratégica, permitindo uma análise mais humanizada do processo decisório, ressaltando que as emoções, a afetividade e os sentimentos não estão relacionados às decisões irracionais.

Como limitação metodológica entende-se que, especificamente na pesquisa apresentada, o contexto da pandemia do coronavírus limitou a apreensão da dimensão afetiva, uma vez que a coleta de dados ocorreu totalmente de modo remoto - por meio de vídeos de reuniões e entrevistas remotas - seguindo as recomendações de distanciamento social. A mediação da tecnologia, ao mesmo tempo que possibilita a coleta de dados em um contexto tão excepcional, limita a análise visual do ambiente e das pessoas.

No caso dos dados secundários - reuniões gravadas por terceiros - o pesquisador fica limitado, por exemplo, aos ângulos e praticantes escolhidos e focados pelo responsável da gravação. Já nas entrevistas remotas, fica-se sujeito à qualidade da internet utilizada por pesquisador e entrevistado, à qualidade de vídeo dos equipamentos utilizados, à qualidade da captação de áudio, à posição da câmera de vídeo. Aspectos que podem dificultas ou inviabilizar a análise dos gestos e das expressões faciais.

Sugere-se que pesquisas futuras, utilizem os pressupostos teóricos-metodológicos de Yves Clot aplicados no tempo da prática, enquanto ela ocorre, visando ampliar a compreensão do fenômeno com a apreensão da dimensão afetiva em tempo real, em suas diversas formas de expressão. Também se sugere que sejam aplicados em outras pesquisas sobre estratégia organizacional que visem compreender as atividades do estrategista. 


\section{REFERÊNCIAS}

BARNARD, C. I. The functions of the Executive. Cambridge: Harvard University Press, 1968.

BODOLICA, V.; SPRAGGON, M. Behavioral Governance and Self-Conscious Emotions: Unveiling Governance Implications of Authentic and Hubristic Pride. Journal of Business Ethics, v. 100, n. 3, p. 535-550, 2011.

BRANDÃO, I. R. Afetividade e transformação social: sentido e potência dos afetos na construção do processo emancipatório. Sobral: Edições Universitárias, 2012.

BULGACOV, S.; BULGACOV, Y. L. M. A Construção do Significado nas Organizações. FACES R. Adm., v. 6, n. 3, p. 81-89, 2007.

BULGACOV, Y. L. M. et al. Contribuições da teoria da atividade para o estudo das organizações. Cadernos EBAPE.BR, v. 12, n. 3, p. 648-662, 2014. Disponível em: <http://www. scielo.br/pdf/cebape/v12n3/v12n3a07.pdf\%0Ahttp://www.scielo.br/scielo.php?script=sci_ arttext\&pid=S1679-39512014000300007〈=pt $>$.

CABANTOUS, L.; GOND, J. P.; JOHNSON-CRAMER, M. Decision theory as practice: Crafting rationality in organizations. Organization Studies, v. 31, n. 11, p. 1531-1566, nov. 2010.

CALABRETTA, G.; GEMSER, G.; WIJNBERG, N. M. The Interplay between Intuition and Rationality in Strategic Decision Making: A Paradox Perspective. Organization Studies, v. 38, n. 4, p. 365-401, 2017. Disponível em: <www.egosnet.org/os>. Acesso em: 26 jan. 2020.

CARVAlHO, M. V. C. de; AGUIAR, W. M. J.; ALFREDO, R. A. Pesquisa e formação docente: possibilidades da autoconfrontação. Revista Educação em Questão, v. 58, n. 58, p. 1-22, 2020.

CHIA, R. The Concept of Decision: A Deconstructive Analysis. Journal of Management Studies, v. 31, n. 6, p. 781-806, 1994.

CLOT, Y. A função psicológica do trabalho. Petrópolis: Editora Vozes, 2006.

CLOT, Y. Trabalho e Poder de Agir. 1 ${ }^{\text {a }}$ ed. Belo Horizonte: Fabrefactum Editora Ltda, 2010.

CLOT, Y. L'affect et sa signification. In: Conscience inconscient émotions. 2. ed. [s.l: s.n.]

COHEN, M. D.; MARCH, J. G.; OLSEN, J. P. A Garbage Can Model of Organizational Choice. Administrative Science Quarterly, v. 17, n. 1, p. 1-25, 1972.

EISENHARDT, K. M.; ZBARACKI, M. J. Strategic decision making. Strategic Management Journal, v. 13, n. 2 S, p. 17-37, 1992.

ELBANNA, S. The constructive aspect of political behavior in strategic decision-making: The role of diversity. European Management Journal, v. 36, n. 5, p. 616-626, 2018. Disponível em: <https://doi.org/10.1016/j.emj.2018.06.006>.

ERICSON, M. Towards a sensed; decision-making approach: From déjà vu to vu jàdé. Management Decision, v. 48, n. 1, p. 132-155, 2010.

FODOR, O. C.; CURŞEU, P. L.; FLEŞTEA, A. M. Affective states and ecological rationality in entrepreneurial decision making. Journal of Managerial Psychology, v. 31, n. 7, p. 1182-1197, 2016. 
GEAR, T. et al. The impact of mood on decision-making process. EuroMed Journal of Business, v. 12, n. 3, p. 242-257, 2017.

HARBOUR, M.; KISFALVI, V. In the Eye of the Beholder: An Exploration of Managerial Courage. Journal of Business Ethics, v. 119, n. 4, p. 493-515, 2014.

HENDRY, J. Strategic Decision Mking, Discourse, And Strategy As Social Practice. Journal of Management Studies, v. 37, n. 7, p. 955-978, 2000.

HODGKINSON, G. P.; HEALEY, M. P. PSYCHOLOGICAL FOUNDATIONS OF DYNAMIC CAPABILITIES: REFLEXION AND REFLECTION IN STRATEGIC MANAGEMENT GERARD. Strategic Management Journal, v. 32, p. 1500-1516, 2011.

JARZABKOWSKI, P.; WOLF, C. An activity theory approach to strategy as practice. In: GOLSORKHI, D. et al. (Ed.). Cambridge handbook of strategy as practice. Second ed. [s.l.] Cambridge University Press, 2015. p. 165-183.

LAROCHE, H. From Decision to Action in Organizations: Decision-Making as a Social Representation. Organization Science, v. 6, n. 1, p. 62-75, 1995.

MAITLIS, S.; OZCELIK, H. Toxic decision processes: A study of emotion and organizational decision making. Organization Science, v. 15, n. 4, p. 375-393, 2004.

MINICK, N. O desenvolvimento do pensamento de Vygotsky: uma introdução a Thinking and Speech (Pensamento e linguagem). In: Uma introdução a Vygotsky. [s.l: s.n.]p. 363.

MINTZBERG, H.; RAISINGHANI, D.; THÉORÊT, A. The Structure of “ Un- structured “ Decision Processes. Administrative Science Quarterly, v. 21, n. 2, p. 246-275, 1976.

NEUMANN, F. Antecedents and effects of emotions in strategic decision-making: a literature review and conceptual model. Management Review Quarterly, v. 67, n. 3, p. 175-200, 2017.

NICOLINI, D.; MONTEIRO, P. The Practice Approach: For a Praxeology of Organisational and Management Studies. In: LANGLEY, A.; TSOUKAS, H. (Ed.). The SAGE Handbook of Process Organization Studies. London: 2017, 2017.

NOLZEN, N. The concept of psychological capital: a comprehensive review. Management Review Quarterly, v. 68, n. 3, p. 237-277, 2018. Disponível em: <https://doi.org/10.1007/ s11301-018-0138-6>.

NUTT, P. C.; WILSON, D. C. Crucial Trends and Issues in Strategic Decision Making. In: NUTT, P. C.; WILSON, D. C. (Ed.). Handbook of Decision Making. [s.1.] John Wiley \& Sons, 2010. p. 3-29.

ORLIKOWSKI, W. J. Practice in research: phenomenon, perspective and philosophy. In: GOLSORKHI, D. et al. (Ed.). Cambridge handbook of strategy as practice. Second ed. [s.l.] Cambridge University Press, 2015. p. 33-43.

PAPADAKIS, V.; THANOS, I.; BARWISE, P. Research on Strategic Decisions: taking stock and looking ahead. In: NUTT, P. C.; WILSON, D. C. (Ed.). Handbook of Decision Making. [s.1.] John Wiley \& Sons, 2010. p. 32-69.

PARAYITAM, S.; OLSON, B. J.; BAO, Y. Task conflict, relationship conflict and agreement-seeking behavior in Chinese top management teams. International Journal of Conflict Management, v. 21, n. 1, p. 94-116, 2010. 
PATRIA, H.; WAHYUNI, S.; KUSUMASTUTI, R. D. Intellectual structure and scientific evolution of strategic decision in the field of business and management (1971 to 2018). Asian Journal of Business and Accounting, v. 12, n. 2, p. 233-286, 2019.

RAMOS, S. C.; TAKAHASHI, A. R. W.; ROGLIO, K. D. D. ANÁLISE DA PRODUÇÃO NACIONAL SOBRE PROCESSO DECISÓRIO NO PERÍODO DE 2004-2014. Contextus - Revista Contemporânea de Economia e Gestão, v. 13, n. 3, 17 dez. 2015.

RECKWITZ, A. Toward a Theory of Social Practices: A Development in Culturalist Theorizing. European Journal of Social Theory, v. 5, n. 2, p. 243-263, 2002.

ROULEAU, L. Studying strategizing through biographical methods: narratives of practices and life trajectories of practitioners. In: GOLSORKHI, D. et al. (Ed.). Cambridge handbook of strategy as practice. Second edi ed. [s.1.] Cambridge University Press, 2015. p. 462-476.

SANDBERG, J.; TSOUKAS, H. GRASPING THE LOGIC OF PRACTICE: THEORIZING THROUGH PRACTICAL RATIONALITY. Academy of Management Review, v. 36, n. 2, p. 338-360, 2011.

SANTOS, M. Apresentação de Obras. Laboreal, v. II, n. 1, p. 34-41, 2006.

SIMON, H. A. Making Management Decisions: the Role of Intuition and Emotion. Academy of Management Executive, v. 1, n. 1, p. 57-64, 1987.

STEPTOE-WARREN, G.; HOWAT, D.; HUME, I. Strategic thinking and decision making: literature review. Journal of Strategy and Management, v. 4, n. 3, p. 238-250, 2011.

TREFFERS, T.; KLARNER, P.; HUY, Q. N. Emotions, time, and strategy: The effects of happiness and sadness on strategic decision-making under time constraints. Long Range Planning, 2020. Disponível em: <https://doi.org/10.1016/j.lrp.2019.101954>.

VAARA, E.; SONENSHEIN, S.; BOJE, D. Narratives as Sources of Stability and Change in Organizations: Approaches and Directions for Future Research. Academy of Management Annals, v. 10, n. 1, p. 495-560, 2016.

VILLAR, E. G. et al. Deciding : decision-making as a social practice. Int. J. Management and Decision Making, v. 17, n. 3, p. 279-298, 2018.

WHITTINGTON, R. The Work of Strategizing and Organizing: For a Practice Perspective. Strategic Organization, v. 1, n. 1, p. 117-125, 2003.

WILSON, D. C.; JARZABKOWSKI, P. Thinking and acting strategically: New challenges for interrogating strategy. European Management Review, v. 1, n. 1, p. 14-20, 2004.

Recebido em: 11-03-2021

Aprovado em: 2-12-2021

Avaliado pelo sistema double blind review.

Disponível em http://mjs.metodista.br/index.php/roc 